\title{
Title: Advanced Cuttings Transport Study
}

\section{Type of Report: Quarterly}

Reporting Period Start Date: July 1, 2002

Reporting Period End Date: Sept 30, 2002

\section{Principal Authors:}

Troy Reed, Principal Investigator

Stefan Miska, Co-Principal Investigator

Nicholas Takach, Co-Principal Investigator

Kaveh Ashenayi, Co-Principal Investigator

Mark Pickell, Project Engineer

Len Volk

Mike Volk

Lei Zhou

Zhu Chen

Crystal Redden

Aimee Washington

Date of Issue: October 30, 2002

DOE Award Number: DE-FG26-99BC15178

The University of Tulsa

600 South College Avenue

Tulsa, Oklahoma 74104 


\section{DISCLAIMER}

This report was prepared as an account of work sponsored by an agency of the United States Government, Neither the United States Government nor any agency thereof, nor any of their employees, makes any warranty, express or implied, or assumes any legal liability or responsibility for the accuracy, completeness, or usefulness of any information, apparatus, product, or process disclosed, or represents that its use would not infringe privately owned rights. Reference herein to any specific commercial product, process, or service by trade name, trademark, manufacturer, or otherwise does not necessarily constitute or imply, its endorsement, recommendation, or favoring, by the United States Government or agency thereof. The views and opinions of authors expressed herein do not necessarily state or reflect those of the United States Government or any agency thereof. 


\section{SUMMARY OF CURRENT TASKS FOR ACTS PROJECT}

This is the first quarterly progress report for Year-4 of the ACTS Project. It includes a review of progress made in: 1) Flow Loop construction and development and 2) research tasks during the period of time between July 1, 2002 and Sept. 30, 2002.

This report presents a review of progress on the following specific tasks:

a) Design and development of an Advanced Cuttings Transport Facility

Task 3: Addition of a Cuttings Injection/Separation System,

Task 4: Addition of a Pipe Rotation System,

b) New Research project (Task 9b): "Development of a Foam Generator/Viscometer for Elevated Pressure and Elevated Temperature (EPET) Conditions",

d) Research project (Task 10): "Study of Cuttings Transport with Aerated Mud Under Elevated Pressure and Temperature Conditions",

e) Research on three instrumentation tasks to measure:

- Cuttings concentration and distribution in a flowing slurry (Task 11), and

- Foam texture while transporting cuttings. (Task 12),

- Viscosity of Foam under EPET (Task 9b)

f) Development of a Safety program for the ACTS Flow Loop.

Progress on a comprehensive safety review of all flow-loop components and operational procedures. (Task 1S).

g) Activities towards technology transfer and developing contacts with Petroleum and service company members, and increasing the number of JIP members.

Note: Research Tasks 6, 7, 8 and 9 were completed during the first three years of this five-year project. 


\section{EXECUTIVE SUMMARY OF PROGRESS}

\section{Flow Loop Construction (Task 3)}

During the first quarter, Year-4 of the ACTS Project, a number of instruments and systems have been successfully calibrated. An exception is calibration of the cuttings injection auger, which has temporarily been deferred in order to first complete twophase experiments with water and air. These two-phase experiments are underway and data are being collected. This data will serve as a reference and baseline for Research Task 10, which includes three-phase tests with liquid-gas-cuttings.

We are still waiting for delivery of 5 high-pressure view ports (2", 3" and three 6"). Earlier, the view ports failed during pressure tests at the manufacturer's facility, but the cause has been determined to be an incorrect assembly procedure and corrective measures are being taken. We hope to have the view ports in hand without too much more delay.

Preliminary designs have been completed for the Year-4 task of drill string rotation. Contacts are being made with several vendors for their input. A presentation will be made at the upcoming Advisory Board Meeting for input from the JIP membership.

Although we have received confirmation from SWACO management that they have approved a donation of a Super-Auto Drilling Choke, we still do not have a schedule yet for when SWACO will deliver it. We are currently attempting to get a commitment on a delivery and installation date.

Additional discussion of the Flow Loop is given in Section 3 of this report.

Development of a Foam Generator/Viscometer for EPET Conditions, (Task 9b).

One of the important findings from the original Research Task 9 is that foam texture (i.e., bubble size, shape \& size distribution) has a primary effect on the apparent viscosity of a foam. This identified the need to have an instrument that can generate a foam with a controlled bubble size and then measure its rheological properties. This has led to the development of a new concept for achieving these objectives. This has become a new instrumentation task and is designated Task 9b. Measurements of foam viscosity will supplement the optical measurements of foam texture that is part of Task 12. TU is currently considering filing an application for a US Patent. If and when a decision is made to file a patent, the appropriate forms will be submitted to the DOE. A description and discussion of the novel Foam Generator/Viscometer is given in Section 4 of this report.

A new graduate student will be using this apparatus to develop standard procedures for how it should be used and to study the viscosity of drilling foams under elevated pressures and temperatures. This work will also include a study of the effects of different amounts of surface roughness on "wall slip", and its effects on measurements of foam viscosity. 
Study of Cuttings Transport with Aerated Mud Under Elevated Pressure and

Temperature Conditions, (Task 10).

Baseline tests have been carried out for water at different flow rates in order to determine the friction factors and wall roughnesses for the 3-in and 4-in pipes and the annular test section. Sieve analyses were conducted to determine the degradation of cuttings when they are transported by a feed auger to load cuttings into the top of the Injection Tower. It was concluded that there is no significant degradation of the particles caused by the loading process. An attempt was made to conduct some tests with water and cuttings, but It was determined that the injection rate delivered by the auger in the Injection Tower will need to be calibrated. In order to accurately control the rate at which cuttings leave the Injection Tower, it will be necessary to calibrate the relationship between auger rotary speed and the rate of cuttings injection based on readings from the load cells under the Injection Tower. In the meantime, air/water flow tests were initiated, and the air/water holdup system has been successfully tested for the case of two-phase flows. The holdup system is designed to enable the measurements of volume fractions of each component when there is a three-phase (liquid-gas-solids) flow. Additional discussion of this task is provided in Section 5.

Research on Instrumentation to Measure Cuttings Concentration and Distribution in a Flowing Slurry, (Task 11).

The modification and testing of the printed circuit board and firmware developed before have continued. The final version of the board has been manually assembled and will be produced as a printed circuit board.

The data acquisition software was modified as well. The preliminary results indicate that we are able to distinguish between different sand concentrations. We further tested the ability of the sensors to see through a solid plastic cap and around a solid pipe in the middle.

In order to account for the nonlinear nature of the slurry flow, a "neural network" computer program will be used to analyze the experimental data and develop a model that will correlate this data. The objective of the model is to produce accurate relationships between ultra-sonic measurements and a variety of slurry flow conditions in all steel annuli. A review of progress on this task is given in Section 6 .

Research on Instrumentation to Measure Foam Properties while Transporting Cuttings, (Task 12).

Some additional minor modifications/improvements to the Dynamic Testing Facility (DTF) have been completed. Alternative ways of measuring bubble sizes and foam quality are being considered. A prototype device for measuring the average bubble size has been constructed. Preliminary tests indicate that it is performing qualitatively as expected. A new, simpler design for a device for measuring foam quality is also being investigated. Software to automatically measure foam bubble size continues to be problematic. The status of this work is reviewed in Section 7 .

Safety Program for the ACTS Flow Loop, (Task 1S) 
The Action Plan continues to be the primary focus of Task 1S. Additional discussion of this task appears in Section 8.

Activities towards Technology Transfer, Developing Contacts with Petroleum \& Service Company Members, and Addition of JIP Members.

The May 2002 Advisory Board Meeting was well attended. In addition to existing JIP members (see Section 9), a number of companies attended as guests. In particular, ExxonMobil had three representatives, Anadarko Petroleum had one person, and Grant Prideco had two people attend this meeting. After attending this meeting, ExxonMobil indicated an interest in joining the project. They will also be sending representatives to the next semi-annual Advisory Board Meeting in November.

In early June, a presentation was made to MI Drilling personnel at their headquarters in Houston. They have also indicated a definite interest in joining the ACTS Project. Contacts with other petroleum and service companies will be pursued. Further discussion of these activities is given in Section 9 of this report. 


\section{TABLE OF CONTENTS}

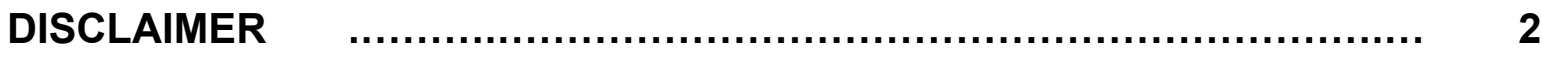

1. SUMMARY OF CURRENT TASKS FOR ACTS PROJECT $\quad \ldots \ldots \ldots \ldots \ldots . . . . . .3$

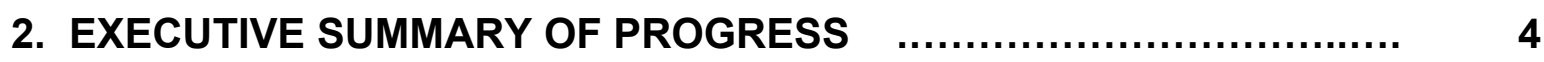

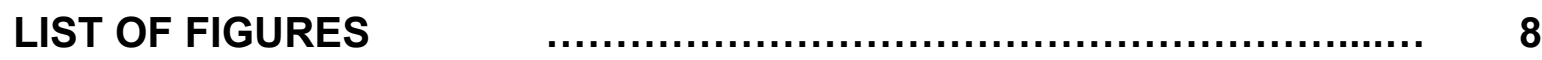

3. ACTF DESIGN AND CONSTRUCTION ACCOMPLISHMENTS $\quad \ldots \ldots \ldots . . . .9$

4. DEVELOPMENT OF A FOAM GENERATOR/VISCOMETER FOR EPET CONDITIONS

5. STUDY OF CUTTINGS TRANSPORT WITH AERATED MUDS UNDER EPAT CONDITIONS

6. DEVELOPMENT OF CUTTINGS MONITORING METHODOLOGY $\quad \ldots . . .32$

7. DEVELOPMENT OF METHODS FOR CHARACTERIZING BUBBLES IN ENERGIZED FLUIDS

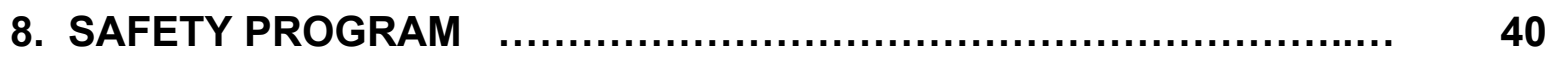

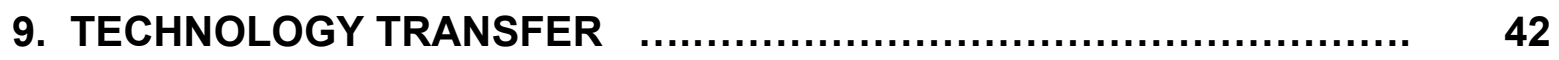




\section{LIST OF FIGURES}

\section{ACTF DESIGN AND CONSTRUCTION (Task 3)}

Figure 3.1 - ACTS Flow Loop with Separation Tower and

Cuttings Injection Hopper with Loading Auger $\ldots \ldots \ldots \ldots \ldots . \quad 9$

\section{DEVELOPMENT OF A FOAM GENERATOR/VISCOMETER FOR ELEVATED PRESSURE AND ELEVATED TEMPERATURE CONDITIONS (Task 9b)}

Figure 4.1 - New Foam Generator/Viscometer Apparatus $\quad \ldots \ldots \ldots \ldots \ldots \ldots . .18$

Figure 4.2 - Apparatus for Injecting Gas and Liquids plus Surfactants $\quad \ldots \ldots \ldots \quad 19$

Figure 4.3 - Foam Generator with Constant Pressure \& Temperature $\quad \ldots . . . . \quad 20$

Figure 4.4 - Couette-Type Viscometer with Constant Pressure \& Temperature 21

STUDY OF CUTTINGS TRANSPORT WITH AERATED MUD UNDER EPET (Task 10, Sec. 6)

Figure 5.1 - Calculated Pipe Roughness at Different Flow Rates $\quad \ldots \ldots \ldots \ldots . \quad 27$

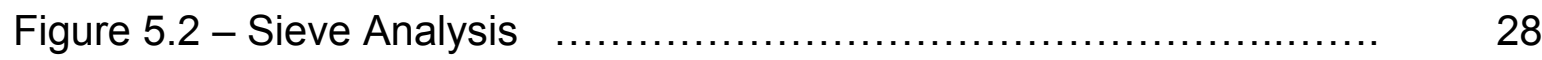

Figure 5.3 - Differential Pressure for Annular Section and 4" Pipe $\quad \ldots . . . . . . \quad 30$

DEVELOPMENT OF METHODS FOR CHARACTERIZING BUBBLES IN ENERGIZED FLUIDS (Task 12)

Figure 7.1 - Dynamic Test Facility as of September $2002 \ldots \ldots \ldots \ldots \ldots \ldots \ldots$

Figure 7.2 - Method for determining the quality of foam $\ldots \ldots \ldots \ldots \ldots \ldots \ldots . \ldots \ldots$ 


\section{ACTF DESIGN AND CONSTRUCTION ACCOMPLISHMENTS}

A considerable amount of time this quarter has been devoted to the calibration process including:

- Calibration of the back pressure chokes;

- Calibration of the liquid/gas separator vent choke;

- Calibration of the liquid hold-up valves, (The objective of a "hold-up" measurement is to determine the volume fraction of each component of a three-phase flow, i.e., gas, liquid and solids.);

- Calibration of the gas expansion tank to measure the amount of gas captured in the annular test section after closing the liquid hold-up valves;

- Calibration of the liquid hold-up measurement software;

- Calibration of the liquid level differential transmitter in the cuttings injection hopper;

- Calibration of the liquid level differential transmitter in the separator tower;

- Calibration of the liquid measurement system;

- Calibration of the gas measurement system;

- Calibration of the nuclear densitometer data collection system;

- Calibration of the pressure and temperature data collection system.

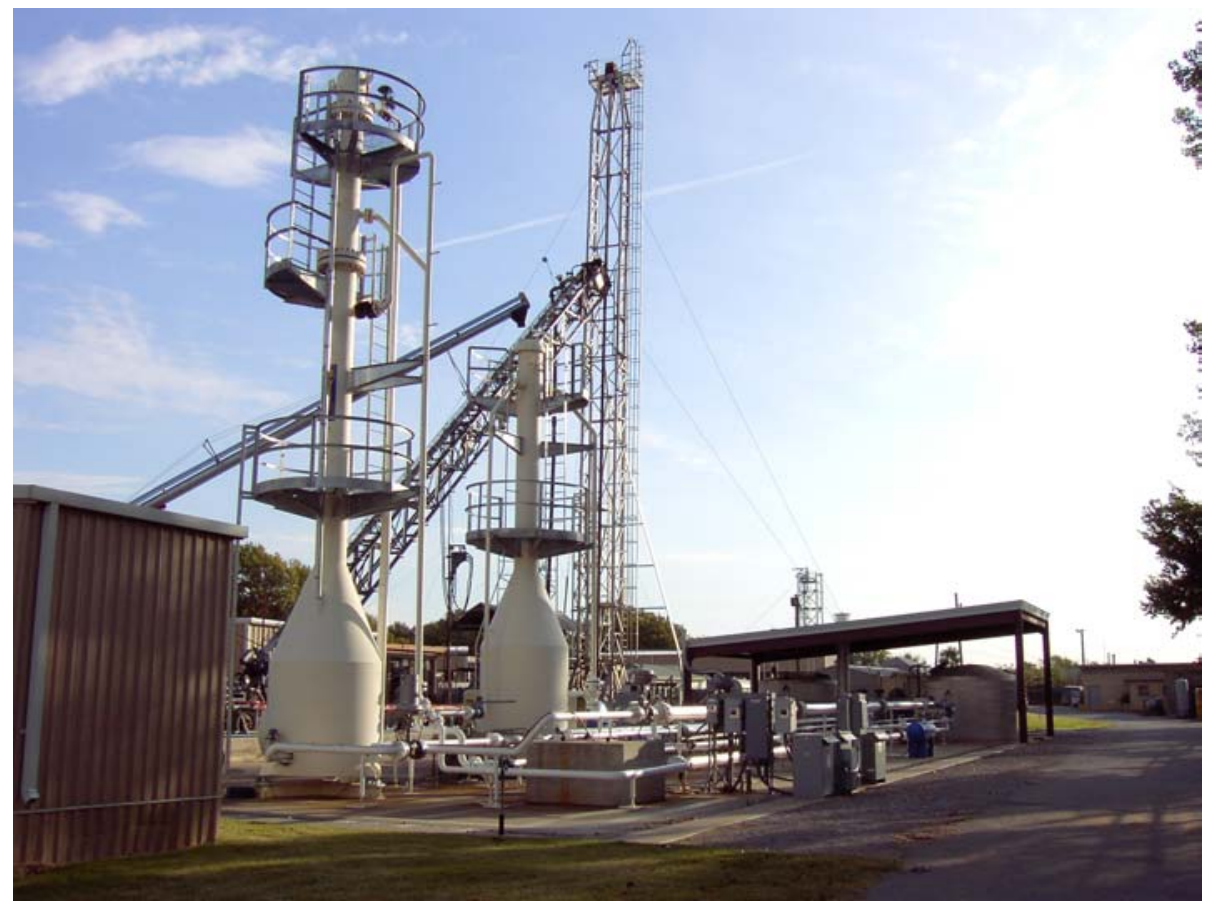

Figure 3.1 ACTS Flow Loop with Separation Tower and Cuttings Injection Hopper with Loading Auger

The only remaining calibration task is the cuttings-feed auger. That task has been deferred until completion of some two-phase experiments, which are now underway and 
data are being collected. This data will provide a reference and a baseline for later three-phase (liquid-gas-cuttings) tests.

In addition to calibration, other tasks completed include:

- Installation of a new cuttings trough for the cuttings loading auger;

- Replacement of two defective temperature transmitters;

- Replacement of one defective pressure transmitter;

- Replacement of the jockey pump seals;

- The fluid end of the Halliburton Pump was re-built with new valve springs, guides, and seats and seals.

- Starter control electronics on the boiler were repaired;

- A new air line was run to the Halliburton Pump starter;

- Designs were completed and all materials ordered and received for the installation of strainers to be placed in the piping that returns flow to the two holding tanks. (This help to minimize any solids that are carried by liquids back to the tanks.) Installation will be completed this winter at such a time as to not interfere with experiments;

- Grease zerks were installed to the cuttings-feed auger in order to prevent "fines" from getting into the bearings;

- Replacement of a defective transmitter on the Micro Motion meter used to measure air flow rates.

Preliminary designs have been completed for next years task of drill string rotation. Contacts are being made with several vendors for their input. A presentation will be made at the upcoming Advisory Board Meeting for input from the JIP membership.

View ports, which were to have been delivered and installed some time ago, have not completed by the vendor as promised. The parts failed during pressure test at the manufacturer's facility. Considerable effort was expended to find out why. In as much as these view ports have never been made before in this size, pressure capability, "full port", and with a smooth constant internal diameter, fully understanding the reasons for failure during the pressure tests was very complicated. The problem was determined to be due to the tolerances in the glass components and the assembly process. That problem is now being fixed, and we hope to have the view ports without too much more delay.

An additional choke is needed between the slurry exiting the flow loop and the Separation Tower. This is necessary because the Separation Tower is designed for a maximum working pressure of 1500 psi versus the test sections of the Flow Loop which can operate at pressures up to 2,000 psi. Hence, this choke will be used to reduce pressures when tests are conducted at pressures above 1500 psi. This will only occur when tests are conducted with conventional (incompressible) drilling fluids. However, this choke can also be used to allow additional expansion of a compressible flow to assist the pumping of a slurry up to the entrance into the Separation Tower. In addition, this new choke must also be able to endure the erosion created by a fast-moving slurry. 
A choke manufactured by SWACO has been proven in field drilling operations to meet this requirement. We have been told by SWACO management that a donation of their Super-Auto Drilling Choke has been approved. We are currently attempting to get a commitment on a delivery and installation date. 


\title{
4. DEVELOPMENT OF A FOAM GENERATOR/VISCOMETER FOR ELEVATED PRESSURE AND ELEVATED TEMPERATURE CONDITIONS (Task 9b)
}

\author{
Investigators: Mark Pickell, Troy Reed and Leonard Volk \\ OBJECTIVES
}

1. Develop a new instrument that will enable the generation of foams with a controllable bubble size and under elevated pressures and temperatures.

2. Develop a process that will enable measurements of the viscous properties of foams that are free of the influences of drainage (syneresis) and bubble coalescence and can quantify the effects of surface roughness on "wall slip".

\subsection{DESCRIPTION OF NEW DESIGN FOR A FOAM GENERATOR/VISCOMETER}

One of the important findings from the Research Task 9 flow-loop tests with foam is that bubble size has a primary effect on the apparent viscosity of a foam. This identified the need to have an instrument that can generate foam with a controlled bubble size and then measure its rheological properties. This has led to the development of a new concept for achieving these objectives. In particular, there is currently a need for an instrument that can generate a foam and measure its viscous properties. The instrument should be capable of controlling the following six variables independently. 1) foam quality (ratio of gas to liquid), 2) pressure, 3) temperature, 4) surfactants and other additives, 5) bubble size, and 6) surface roughness inside a viscometer. A survey of different manufacturers of viscometers and rheometers revealed that there is currently no commercially available instruments designed to accomplish the above list of measurements for foams. The following is a description of the concept of the new apparatus and the process. The concept was developed and designed by Mark Pickell, Troy Reed and Leonard Volk

As noted above the apparatus is termed a Foam Generator/Viscometer. It provides a means by which the rheology of foams, emulsions or other shear-sensitive media may be measured. Liquid components (such as surfactant and water) are selectively combined with a gas (such as nitrogen, air or other gases) in various ratios, mixed to a desired consistency, and allowed to flow under controlled conditions (pressure, temperature, and flow rate) through a modified (variable surface roughness) Couettetype rotary Viscometer at such a rate that the viscosity of the foam is determined while its properties (bubble size, quality, pressure, temperature, and viscosity) are maintained constant.

\subsection{SUMMARY OF THE APPARATUS AND PROCESS}

The Apparatus described herein allows the desired ratio of gas and liquid to be precisely placed into a mixing cell that is designated herein as the Foam Generator. Foam is formed by means of a propeller (which can have a variety of designs) driven 
over a wide-range of rotary speeds by a variable speed motor. In order to generate a uniform foam with the desired properties, the inside of the foam generator also has a special geometry to promote mixing, and the fluid mixture can additionally be circulated through an external mixing loop for the purpose of achieving a homogeneous mixture. Also, the Generator is equipped with a floating piston that allows the foam to be pressurized. An appropriate heat source enables the foam to be heated. The foam characteristics (e.g., bubble size and gas/liquid ratio) are visually and electronically assessed in the external mixing loop via two view ports to ascertain when the foam has stabilized and reached steady state at the desired conditions. In addition, two other view ports permit the monitoring of the foam both upstream and downstream of the Viscometer. Foam enters the top of the Viscometer and leaves through the bottom. This assures that any liquid drainage from the foam is quickly removed and does not affect the measurement. If the foam characteristics change within the Viscometer, the flow rate can be adjusted to reduce or increase the average fluid residence time within the Viscometer. Furthermore, the interior surfaces of the Viscometer are modified with different surface roughnesses to assess the effects of this variable on wall slip and measurements of foam viscosity.

The Process begins with combining liquid components in desired ratios and quantities in an open container. From there, measured quantities of the liquids are pumped, at near atmospheric pressure, into a unique Foam Generator. The Generator is then isolated by means of valves, and gas is injected, inside with the liquids, to a desired pressure. The temperature of the foam generator is then raised to a desired level by means of an appropriate heat source (e.g., an electrical heater or a recirculating heat bath). The temperature is maintained by a thermostat connected to a thermocouple and by insulation. Next, a propeller inside the foam generator is rotated, at a desired speed and for a selected length of time, to generate the foam. Propeller design, rotation speed and length of mixing time determine the amount of shear energy applied and the resulting bubble size, which affects foam viscosity. The Generator is uniquely constructed to permit proper loading and mixing of components. The shape of the propeller, its shroud, and contouring of the bottom side of the piston are designed to circulate the mixture up through the center of the Generator and then downward along the chamber walls to promote uniform mixing. In addition to the mechanics of the Generator, a circulating pump is available. It may be arranged to pump from either the top to the bottom of the Generator or from the bottom to the top and, thereby, further enhance mixing. Once mixing has been completed, valves are manipulated to apply high-pressure gas to the top of the piston. This piston maintains constant pressure on the foam. A micrometer valve downstream of the modified Couette-type rotary Viscometer is opened to cause flow from the Generator to the Viscometer. This is an essential feature of the Process. The Generator and the Process are designed to carefully maintain integrity of the foam. The rate at which the constant-pressure foam flows out of the Generator and across to the Viscometer is determined by measuring the rate of movement of the piston. The flow rate of the foam through the Viscometer is precisely calculated at all times. Pressure and temperature are constantly monitored. The foam is visually and electronically assessed at view ports upstream and 
downstream of the Viscometer to assure that the flow rate of the foam is sufficient to prevent any changes in bubble size or viscosity during a test.

The Process for creating a constant-property foam, at elevated pressures and temperatures, and causing it to flow through a Couette-type Viscometer, with variable surface roughness, is unique. Furthermore, the Foam Generator for mixing the components uniformly and transferring the foam to a Viscometer is novel in its design and function. In addition, the process for maintaining the foam's integrity, under controlled conditions as it is conveyed to and through a Viscometer, is also new and original.

\subsection{DETAILED DESCRIPTION}

Figure 1 is a schematic of the Foam Generator/Viscometer apparatus and process (the Process). The Process includes a means to make a liquid-gas-surfactant foam by selectively mixing the components in various ratios, vary the resulting bubble size by adjusting the amount of mixing or shear energy applied, and measure the resulting viscosity. Temperature and pressure are controlled throughout the Process. Bubble texture (size, shape, and size distribution) are monitored going into the viscometer and coming out of the viscometer. The particulars of the viscometer are varied depending on the bubble size. These include systematic variations in gap spacing between a stationary cylindrical cup and the OD of a rotor, rotor design and changing surface roughness on the internal surfaces of the Viscometer.

Given its complexity, the Apparatus is divided into three parts as shown in Figures 2, 3, and 4.

Figure 2 displays that portion of the Apparatus that deals with dispensing the constituent gases and fluids to the rest of the Process.

Gas, contained under pressure in Cylinder 1, is dispensed through Tank Valve 2 and Pressure Regulator 4. Pressure inside the gas cylinder, "upstream" of Pressure Regulator 4, is observed on Pressure Gauge 3. Pressure "downstream" of Pressure Regulator 4 is observed on Pressure Gauge 6. Pressure Regulator 7 further refines the precise pressure of gas dispensed to the Process. This pressure is measured by the high precision Pressure Gauge 9. By manipulation of the Valves 8, 53, and 13, the gas may be dispensed to the process through either Line 15 or Line 16 . All components described above, from Pressure Regulator 4, through and including Lines 15 and 16, are interconnected with Stainless Steel Tubing 5.

Liquids are pre-mixed in a volume-calibrated Container 10 prior to being dispensed to the Process through a low-pressure, Flexible Tubing 11, and Pump 12. The volume of liquids dispensed to the Process is an operational parameter of the pump.

The sequence of operations is critical to the proper function of the components displayed in Figure 2. The liquids must be pre-mixed and dispensed into the Process first. Next, the gas must then be dispensed into the Process only after the liquids. 
Figure 3 displays that portion of the Process that deals with the generation of foam. As with the components displayed in Figure 2, the sequence of operations is critical.

First, liquids are dispensed to the Process, through Line 15, through Port 33, into the Foam Generator 27. As the liquid volume increases inside the foam generator, the Piston 18 begins to rise off of its resting place upon Stops 31 .

Once the desired volume of liquids has been dispensed into the Generator, Valves 8 , 53, and 13 (see Figure 2) are manipulated to allow gas to flow through Regulator 7, (see Figure 2) and Line 15, thereby adding a gas volume to the liquid volume, Piston 18 is raised to its maximum height against Cap 28, and both the liquids and gas inside the Generator are at a selected pressure.

Foam generation is initiated by rotating Propeller 21 with Motor 23. The speed of rotation is set by Control 24. The rotation speed and propeller design enables control of the rate of energy input to the fluid. Flow inside the foam generator is upward in the center of the chamber as the propeller picks up gas, liquid, and foam from the bottom and propels it upward. Flow is diverted downward along the sides of the chamber via the specially contoured Piston 18 . The propeller is allowed to run a sufficient length of time and speed to achieve the desired results. Additional mixing can be achieved by drawing liquids, gas, and foam from either the top or bottom of the foam generator with Pump 34 and circulating back to the opposite end of the mixing chamber. Flow is through Port 33, Valve 36, flexible high-pressure Hose 32, Hollow Shaft 19, and Piston 18. Foam characteristics (bubble size and gas/liquid ratio) are visually and electronically assessed at view ports 57 and 58 to indicate when the foam has stabilized (reached steady state) at the desired conditions.

After a satisfactory foam has been generated, Valves $53,54,55$, and 8 are manipulated to direct gas pressure to the top of Piston 18 and into Line 42. By pressurizing Line 42, which connects the Generator with the Viscometer, this allows a smooth continuous flow of the final foam sample between the two devices when the micrometer valve is opened downstream of the Viscometer.

Other features of the Foam Generator system, that are displayed in Figure 3, include Vent Valve 37, Drain Valve 39, Drain Line 38, O-ring Seals such as 29 and 30, Pump Motor 35, a means by which to measure Piston Movement 20, a means by which the temperature inside the Generator may be increased 25, Thermal Insulation 26, a special propeller Shroud 21 to direct flow upward, Pressure Gauge 40, Thermocouple 56, a third View Port 41 which allows visual and optical measurements of the foam, and Line 42 through which foam is dispensed to the Viscometer section of the Process. All of these components combine in various sequences to fill, empty, flush, and drain both the Generator and the Viscometer.

Figure 4 is the foam Viscometer section. Foam enters through Line 42 into the Viscometer Cup 43, where viscosity is measured by the Viscometer 44 . It is an 
essential component of the process that foam can be allowed to flow, at whatever rate is needed, during the viscometer measurement process in order to compensate for any foam degradation such as drainage (syneresis) and/or bubble coalescence. Flow is controlled by a Micrometer Valve 48, which allows flow rate to be controlled by varying the opening of the valve. Pressure is monitored by Pressure Gauges 40 and 49 and is controlled by maintaining a specified gas pressure above Piston 18. The foam is visually and electronically assessed at view port 50 to assure that it is the same as the foam that enters the Viscometer and is evaluated at View Port 41 (see Figure 3).

The Viscometer includes a Heater 45, which enables control and selection of temperature of the test fluids, and Thermal Insulation 46 to maintain a uniform temperature inside the Viscometer Cup 43.

Drain Receptacle 52 receives waste from Line 51 and Line 38.

An alternate means of controlling the rate of flow through the Viscometer cup, instead of flowing directly into Drain Receptacle 52 , is to direct flow into a pressurized container of such size that all of the liquid and gas components of the foam are contained therein. Flow is controlled by Micrometer Valve 48, which, in this case, is located on the top of the pressurized container and is used to control flow by allowing the gaseous phase only to be vented. This permits better control of flow rate rather than have an intermittent flow of liquid and gas passing through the micrometer valve. In between tests, liquids are drained from the pressurized container.

\subsection{LIST OF NEW AND NOVEL FEATURES}

1. A new and novel device has been designed that can be used to generate foams, emulsions and other mixtures of heterogeneous fluids. This device is referred to as a Foam Generator. It includes the following elements: 1) a high-pressure mixing chamber that has a movable piston to vary volume inside the chamber, 2) a device to measure the rate of movement of the piston, e.g., a Linear Differential Voltage Transformer, 3) a propeller that can be changed to permit the use of a variety of designs, 4) a variable speed drive motor than turn the propeller over a wide range of rotary speeds, 5) a propeller shroud that enhances upward movement of the fluids when the propeller is turning, 6) a contoured geometry of the inside surface of the moveable piston that assists recirculation of the fluids back down along the sidewalls of the chamber, 7) a heater that enables control of temperature of fluids inside the mixing chamber, 8) a hollow piston shaft and ports that permits recirculation of fluids from either the top back to the bottom or vice versa, 9) a pump and drive motor to recirculate fluids through the external flow path and thereby enhance mixing, and 10) view ports to enable visual observations of the foam and/or optical measurements of the foam properties such as bubble size.

2. The following auxiliary components are necessary for proper functioning of the Foam Generator. 1) a container with a calibrated volume for the liquid components, e.g., water plus surfactants and other additives, 2) a low-volume pump that can meter the amount of liquids that are pumped into the mixing chamber, and 3) a high-pressure gas 
source with pressure regulators, gauges and control valves to introduce gas at a selected pressure into the mixing chamber and above the moveable piston to maintain the selected pressure on the fluids when they flow across to the Viscometer.

3. The Viscometer for the Process must include the following features. 1) ports that permit fluids to enter at the top of the measurement cup and leave at the bottom, 2) variable rotor designs and sizes, 3) variable rotary speeds, 4) designed to contain high pressures, and 5) a heating system that enables control of temperature of the test fluids.

4. The following auxiliary components are necessary for proper functioning of the Viscometer. 1) a pressure gauge on the incoming flow line, 2) a pressure gauge on the exit flow line, 3) a view port on the incoming flow line, 4) a view port on the exit flow line, 5) a pressurized container to receive fluids exiting the Viscometer, and 6) a downstream micrometer valve to control flow through the Viscometer.

5. The complete Process for generating a foam and measuring its viscous properties is unique and original. The Process includes the following steps. 1) pump a measured volume of liquids into the mixing cell, 2) fill the cell with gas at a known pressure, 3) charge flow line between the Generator and Viscometer with the same gas pressure, 4) turn on propeller and the external recirculation pump and let run until the desired mixture properties are achieved, 5) determine mixing time via observations of the fluids through view ports above and below the recirculation pump, 6) vent equilibrated foam to viscometer while maintaining constant pressure by applying gas pressure on the top side of the piston in the mixing cell to force it downward, 7) begin measuring foam viscosity, 8) adjust flow rate through Viscometer until a steady reading is achieved, and 9) compare foam properties such as bubble size via observations and measurements through view ports upstream and downstream of the Viscometer.

TU is presently evaluating the filing of a US patent application for this new instrument. If the decision is made to file for a patent, then the appropriate forms will be submitted to the DOE. In addition, the details will be shared with the ACTS JIP members. 


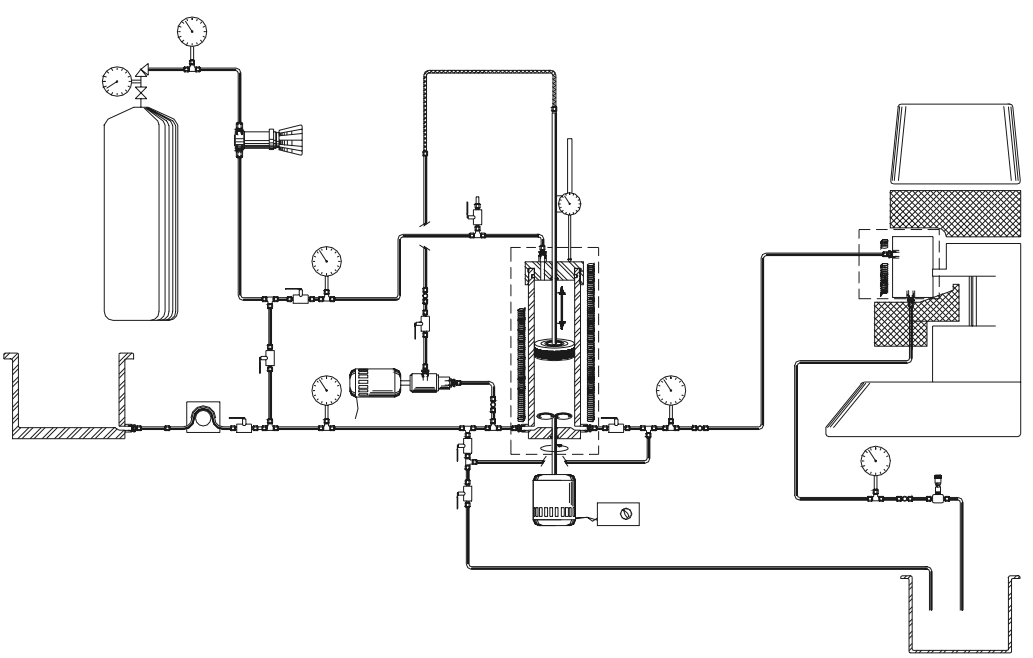

Figure 4.1

New Foam Generator / Viscometer Apparatus 


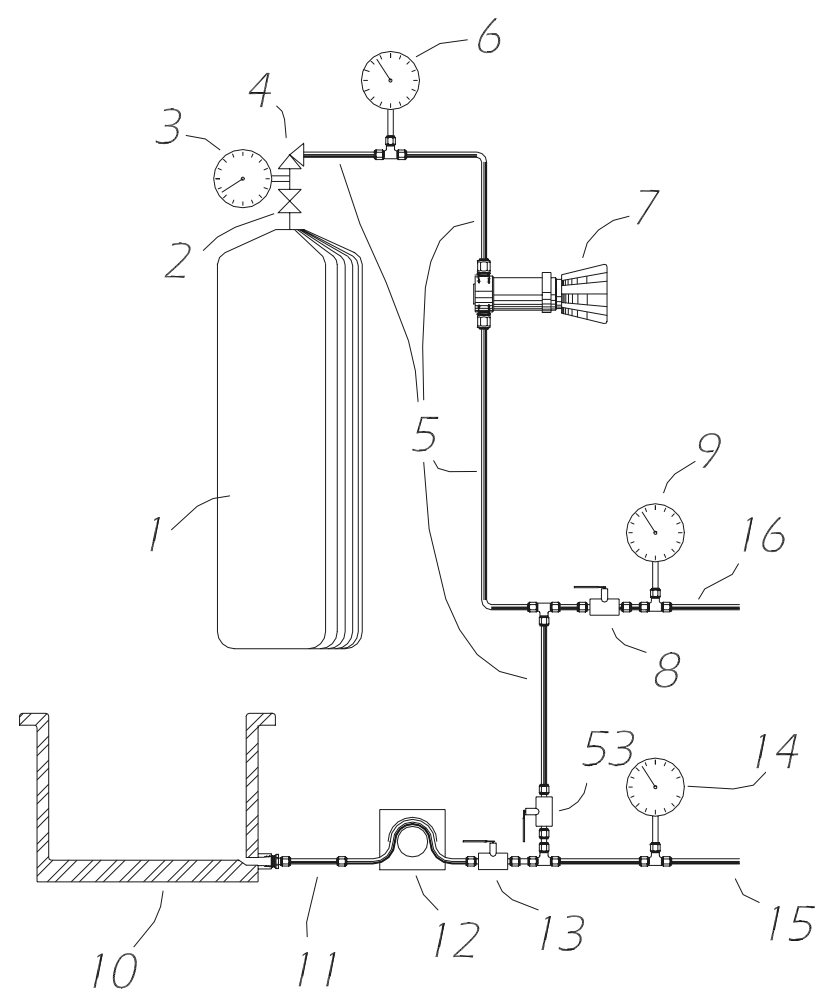

Figure 4.2

Apparatus for Injecting Gas and Liquids plus Surfactants 


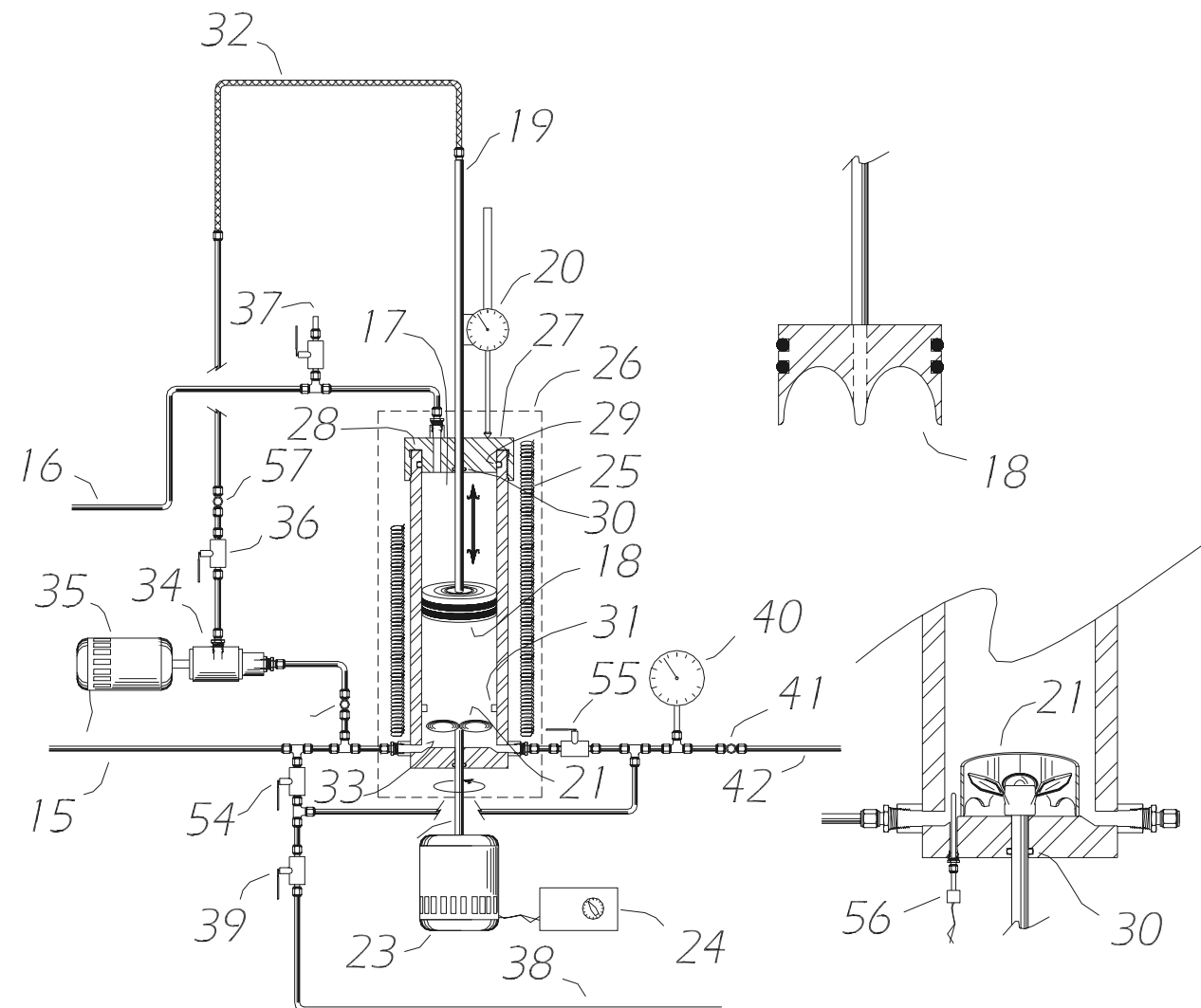

Figure 4.3

Foam Generator with Constant Pressure \& Temperature Features 


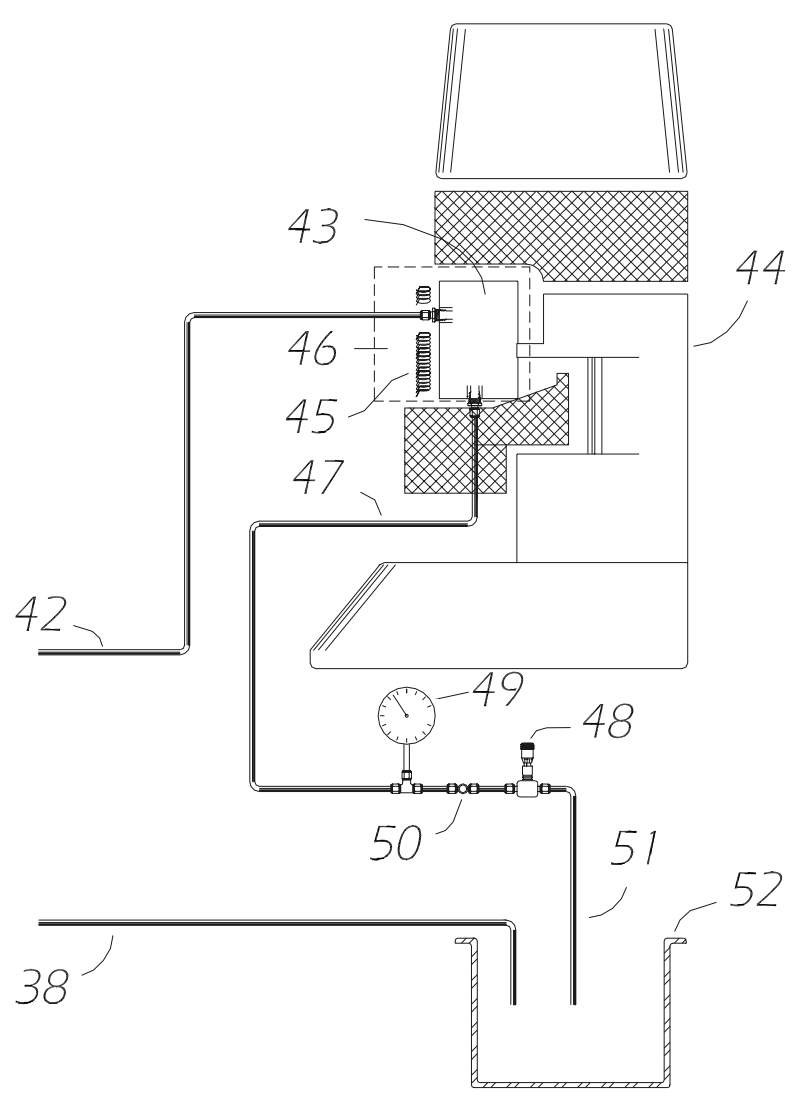

Figure 4.4

Couette-Type Viscometer with Constant Pressure \& Temperature Features 


\title{
4.5 DEVELOPMENT OF STANDARD PROCEDURES FOR USING THE NEW FOAM GENERATOR/VISCOMETER
}

\author{
Investigator: Aimee Washington (MS Student) \\ Project Title: "An Experimental Study of the Viscosity of Drilling Foam Using \\ a Foam Generator/Viscometer"
}

\section{Part of TASK 9b OBJECTIVES}

- Discover a method of applying a uniform rough surface to the inside of the cup and the outside of the rotor in a Couette-type Viscometer.

- Discover a way to quantify the rough surface

- Calibrate the RS300 rheometer that will be used for viscosity measurements.

- Conduct preliminary tests using commercially available foams

- Connect the Rheometer and Foam Generator and develop the procedures that are necessary to control bubble size and measure the viscous properties of a foam under controlled pressure and temperature conditions.

\section{Summary of Recent Work}

A major factor concerning the viscosity of foam is the theory of "wall slip". In order to quantify this phenomenon, a variety of roughnesses must be applied to the surfaces, that the foam is in contact with, while the viscosity measurements are being made. A number of procedures for coatings and epoxies were considered, but none would create a uniform surface on the cylindrical surfaces in a time and cost efficient manner. It was finally decided that a uniform surface could be achieved by machining the rotor and cup in a specified design and at specified dimensions. By varying these dimensions, a variety of roughnesses could be created. Then the question remained: how could these rough surfaces be quantified? After researching different manufacturers of instruments for roughness measurement, the Surftest 401 was purchased to provide an accurate quantification of surface finishes. While the application and quantification of the rough surfaces were being considered, Thermo Haake personnel installed an RS300 Rheometer.

The theory behind viscometers and rheometers has been studied, as well as the manuals for the RS300 Rheometer. Presently, two different Canon viscosity standardized oils at constant temperatures are being used to calibrate the RS300 Rheometer.

\section{Future Plans}

The calibration process will be completed and verified using the two calibration oils and deionized water. Then preliminary tests will be run using commercially available foams like shaving cream, in order to become familiar with the differences that the rough surfaces have on foams. Finally, the foam generator will be connected to the RS300 Rheometer, and the viscosity of dynamic foam, one that is moving through the Rheometer, will be tested against varying degrees of rough surfaces on the cup and rotors in order to obtain an accurate viscosity for a particular foam. It is expected that 
"wall slip" will decrease as roughness increases. The required minimum surface roughness to eliminate "wall slip" is also expected to be a function of foam quality (ratio of gas to total foam volume) and bubble size.

Finally, standard procedures will be developed for using the new apparatus to study the viscous properties of foams under a variety of conditions. 


\title{
5. STUDY OF CUTTINGS TRANSPORT WITH AREATED MUD UNDER ELEVATED PRESSURE AND TEMPERATURE CONDITIONS (TASK 10)
}

\author{
Investigator: Lei Zhou (Ph.D. Candidate)
}

\section{OBJECTIVES}

1. Develop two-phase flow model for aerated fluids at elevated pressure and temperature inside annuli in a horizontal position without pipe rotation.

2. Determine experimentally the cuttings transport ability of aerated fluids under elevated pressure and temperature conditions.

3. Determine the optimum gas/liquid flow rates for cuttings transport.

4. Develop a computational tool to calculate pressure loss in aerated fluids flowing under elevated pressure and temperature conditions.

\subsection{Baseline Tests (water only) for Pipe Roughness and Friction Factor}

Water has been pumped through all flow sections of the flow loop at different flow rates. Tests have been repeated 4 times. The purpose of that is to measure the pipe roughness and related friction factor for the hydraulic model. By recording the differential pressure data, we can back calculate the pipe roughness and friction factor. Table 5.1 contains the results of calculations.

TABLE 5.1 - WALL ROUGHNESS VALUES

\begin{tabular}{|c|c|c|c|}
\hline Flow rate(GPM) & Roughness 4" & Roughness 6"x3.5" & Roughness 3" \\
\hline 106 & $2.824 \mathrm{E}-04$ & $1.665 \mathrm{E}-04$ & $9.663 \mathrm{E}-05$ \\
\hline 151 & $9.687 \mathrm{E}-05$ & $1.528 \mathrm{E}-04$ & $8.839 \mathrm{E}-05$ \\
\hline 200 & $4.471 \mathrm{E}-05$ & $1.683 \mathrm{E}-04$ & $1.018 \mathrm{E}-04$ \\
\hline 251 & $5.252 \mathrm{E}-05$ & $1.740 \mathrm{E}-04$ & $1.182 \mathrm{E}-04$ \\
\hline 301 & $4.469 \mathrm{E}-05$ & $1.725 \mathrm{E}-04$ & $1.212 \mathrm{E}-04$ \\
\hline 317 & $4.836 \mathrm{E}-05$ & $1.546 \mathrm{E}-04$ & $7.644 \mathrm{E}-05$ \\
\hline AVG & $9.493 \mathrm{E}-05$ & $1.648 \mathrm{E}-04$ & $1.004 \mathrm{E}-04$ \\
\hline
\end{tabular}

A MathCAD program has been written to perform the required calculations. 


\section{Sample calculations are shown below}

$\begin{array}{llllll}\text { L2: }=52.9 & \text { D2: }=1.918 & \text { D2: }=\mathrm{D} 2 \times \frac{0.3048}{12} & \mathrm{~L} 2:=\mathrm{L} 2 \times 0.3048 & \mathrm{~A} 2:=\frac{\pi \times \mathrm{D} 2^{2}}{4} & \mathrm{~A} 2=1.864 \times 10^{-3} \\ \mathrm{~L} 3:=52.9 & \mathrm{D} 3:=2.9 & \mathrm{D} 3:=\mathrm{D} 3 \times \frac{0.3048}{12} & \mathrm{~L} 3:=\mathrm{L} 3 \times 0.3048 & \mathrm{~A} 3:=\frac{\pi \times \mathrm{D} 3^{2}}{4} & \mathrm{~A} 3=4.26 \times 10^{-3} \\ \mathrm{~L} 4:=66.6 & \mathrm{D} 4:=3.826 & \mathrm{D} 4:=\mathrm{D} 4 \times \frac{0.3048}{12} & \mathrm{~L} 4:=\mathrm{L} 4 \times 0.3048 & \mathrm{~A} 4:=\frac{\pi \times \mathrm{D} 4^{2}}{4} & \mathrm{~A} 4=7.41710^{-3} \\ \text { LA }:=57.4 & \text { ID }:=5.761 & \text { OD: }:=3.5 & \mathrm{ID}:=\mathrm{ID} \times \frac{0.3048}{12} & \mathrm{OD}:=\mathrm{OD} \times \frac{0.3048}{12} & \end{array}$

$\mathrm{Aa}:=\frac{\pi \times\left(\mathrm{ID}^{2}-\mathrm{OD}^{2}\right)}{4} \quad \mathrm{Aa}=0.011$

Dhy:=ID-OD

Dhy $=0.057 \quad \mu:=8 \times 10^{-4}$

$\mathrm{DL}:=\sqrt{\mathrm{ID}^{2}+\mathrm{OD}^{2}-\frac{\mathrm{ID}^{2}-\mathrm{OD}^{2}}{\ln \left(\frac{\mathrm{ID}}{\mathrm{OD}}\right)}} \quad \mathrm{DL}=0.047 \quad$ Deq: $=\frac{\mathrm{DL}^{2}}{\mathrm{Dhy}} \quad$ Deq $=0.038$

$\mathrm{T}:=92.68$

$\rho:=9.998395689100+6.798299989100^{-2} \times \mathrm{T}-9.10602556410^{-3} \times \mathrm{T}^{2}+1.00527298910^{-4} \times \mathrm{T}^{3}$ 


$$
\begin{aligned}
& \text { Q }:=200 \quad \text { DP4 }:=17.768 \times 249 \quad \text { DP6 }:=24.469 \times 249 \quad \text { DP3 }:=84.661 \times 249 \\
& \mathrm{Q}:=\frac{\mathrm{Q}}{264.2 \times 60} \quad \mathrm{Q}=0.013 \\
& \mathrm{~V} 4:=\frac{\mathrm{Q}}{\mathrm{A} 4} \quad \mathrm{~V} 6:=\frac{\mathrm{Q}}{\mathrm{Aa}} \quad \mathrm{V} 3:=\frac{\mathrm{Q}}{\mathrm{A} 3} \quad \mathrm{~V} 2:=\frac{\mathrm{Q}}{\mathrm{A} 2} \\
& \operatorname{Re} 4:=\frac{\rho \times \mathrm{V} 4 \times \mathrm{D} 4}{\mu} \quad \operatorname{Re} 6:=\frac{\rho \times \mathrm{V} 6 \times \mathrm{Deq}}{\mu} \quad \operatorname{Re} 3:=\frac{\rho \times \mathrm{V} 3 \times \mathrm{D} 3}{\mu} \quad \operatorname{Re} 2:=\frac{\rho \times \mathrm{V} 2 \times \mathrm{D} 2}{\mu} \\
& \text { Re4 }=2.07 \times 10^{5} \quad \operatorname{Re} 6=5.724 \times 10^{4} \quad \operatorname{Re} 3=2.731 \times 10^{5} \quad \operatorname{Re} 2=4.129 \times 10^{5} \\
& \mathrm{DP} 4=2 \times \mathrm{f} 4 \times \rho \times \frac{\mathrm{V} 4^{2}}{\mathrm{D} 4} \quad \mathrm{f} 4:=\frac{1}{2} \times \frac{\mathrm{DP} 4}{\left(\rho \times \mathrm{V} 4^{2}\right)} \times \mathrm{D} 4 \quad \mathrm{f} 4=0.074 \\
& \text { DP6 }=2 \times \mathrm{f} 6 \times \rho \times \frac{\mathrm{V} 6^{2}}{\text { Dhy }} \quad \text { f6 }:=\frac{1}{2} \times \frac{\mathrm{DP} 6}{\left(\rho \times \mathrm{V} 6^{2}\right)} \times \text { Dhy } \quad \text { f6 }=0.124 \\
& \mathrm{DP} 3=2 \times \mathrm{f} 3 \times \rho \times \frac{\mathrm{V}^{2}}{\mathrm{D} 3} \quad \mathrm{f3}:=\frac{1}{2} \times \frac{\mathrm{DP} 3}{\left(\rho \times \mathrm{V}^{2}\right)} \times \mathrm{D} 3 \quad \mathrm{f} 3=0.088 \\
& \varepsilon:=0.00001 \quad \mathrm{f} 4:=\frac{\mathrm{f} 4}{4} \quad \mathrm{f} 6:=\frac{\mathrm{f} 6}{4} \quad \mathrm{f3}:=\frac{\mathrm{f} 3}{4} \\
& g(\varepsilon):=2 \times \log \left(\frac{2.51}{\operatorname{Re} 4 \times \sqrt{\mathrm{f} 4}}+\frac{\frac{\varepsilon}{\mathrm{D} 4}}{3.715}\right)+\frac{1}{\sqrt{\mathrm{f} 4}} \quad \varepsilon:=\operatorname{root}(\mathrm{g}(\varepsilon), \varepsilon) \quad \varepsilon=4.472 \times 10^{-5} \\
& \varepsilon:=0.00001 \\
& \mathrm{~g}(\varepsilon):=2 \times \log \left(\frac{2.51}{\operatorname{Re} 6 \times \sqrt{\mathrm{f} 6}}+\frac{\frac{\varepsilon}{\mathrm{Deq}}}{3.715}\right)+\frac{1}{\sqrt{\mathrm{f} 6}} \quad \varepsilon:=\operatorname{root}(\mathrm{g}(\varepsilon), \varepsilon) \quad \varepsilon=1.682 \times 10^{-4} \\
& \varepsilon:=0.0001 \\
& \mathrm{~g}(\varepsilon):=2 \times \log \left(\frac{2.51}{\operatorname{Re} 3 \times \sqrt{\mathrm{f3}}}+\frac{\frac{\varepsilon}{\mathrm{D} 3}}{3.715}\right)+\frac{1}{\sqrt{\mathrm{f3}}} \quad \varepsilon:=\operatorname{root}(\mathrm{g}(\varepsilon), \varepsilon) \quad \varepsilon=1.017 \times 10^{-4}
\end{aligned}
$$


Absolute pipe roughness versus flow rate is given in Figure 5.1. It should be noticed here that inner pipe is supported by 13 stands to keep it in the concentric configuration. They may cause different friction at different flow rates.

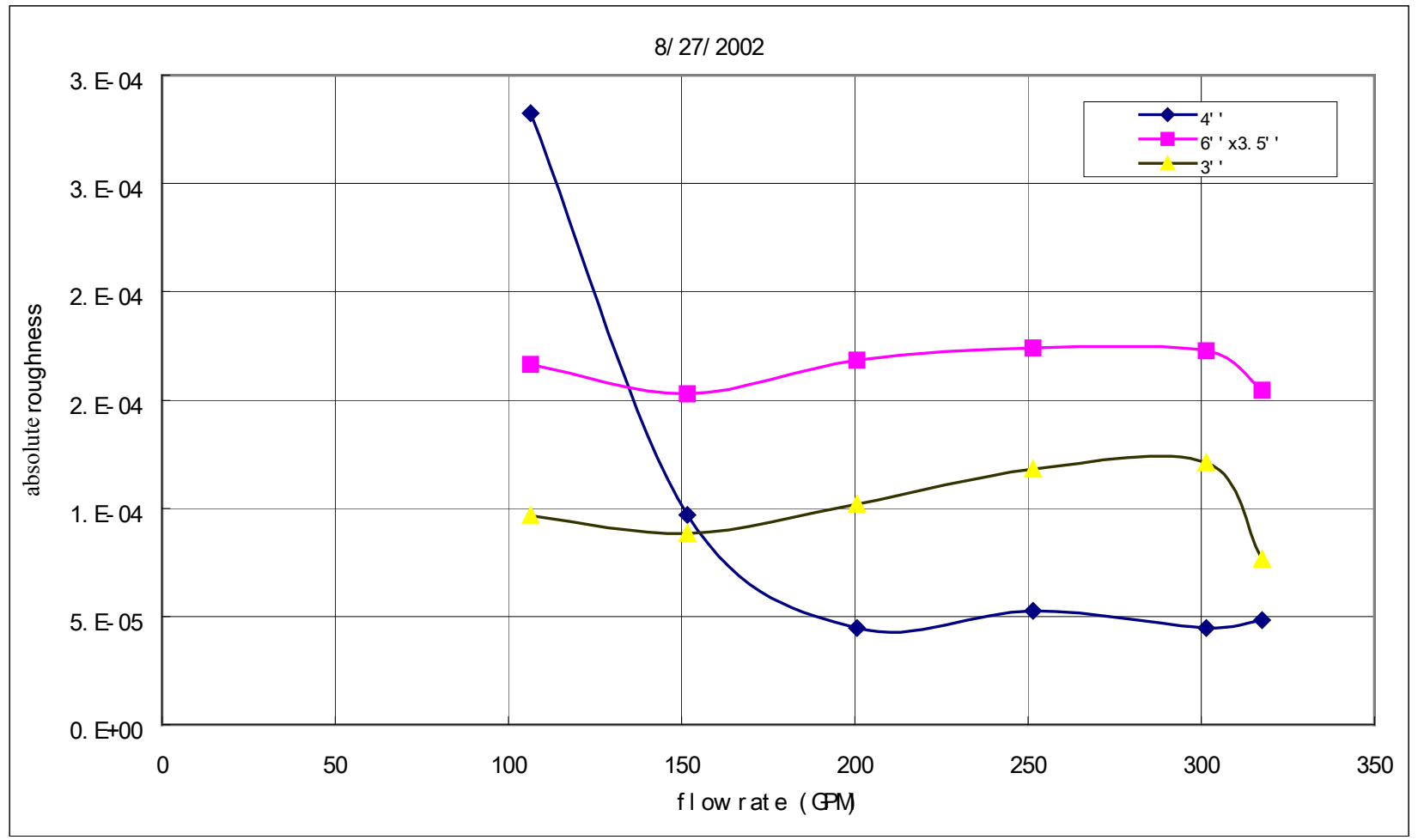

Figure 5.1 Calculated Pipe Roughness at Different Flow Rates

\subsection{Sieve Analysis of Transferred Cuttings}

About $5000 \mathrm{~g}$ of cuttings were collected from the top of injection tower right after the auger transferring. Another $5000 \mathrm{~g}$ of cuttings were collected from the inlet tank of auger. A series of U.S. standard sieves were used to performance the analysis. Results are given in Figure 5.2.

From Figure 5.2, we can see the degradation during the loading of cuttings appears to be ignorable. Another concern is the possible degradation during the cuttings transport tests. This will be addressed in the future testing. 


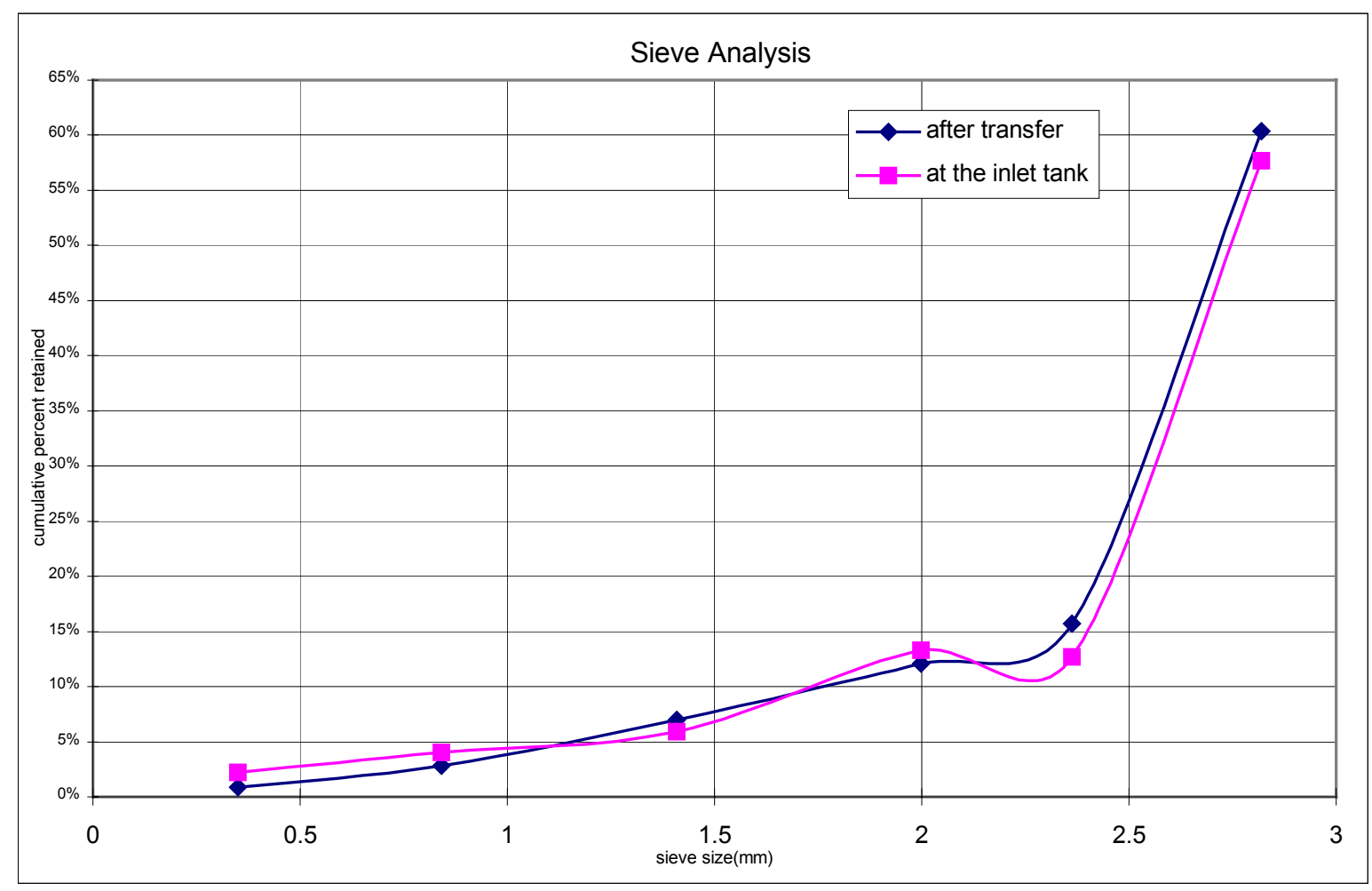

Figure 5.2 Sieve Analysis

\subsection{Water Cuttings Test}

An attempt was made to flow water and cuttings. During the test, cuttings were injected into the flow loop, and returned to the collection tower. Injection auger was turned at 45 RPM, and water flow rate was 120 GPM. It appeared that a steady state was reached. This means the weight change of the Injection Tower is equal to the weight change of the Collection Tower. In addition, differential pressures was recorded and also the densitometer readings. In order to obtain accurate measurements of the weight of cuttings leaving the Injection Tower, it will be necessary to calibrate the relationship between auger rotary speed and the indicated rate of cuttings injection based on readings from the load cells for the Injection Tower.

\section{Preliminary Air Water Tests at Elevated Pressure and Temperature}

Parameters measured during the test are: temperature, differential pressure, mixture density, and liquid holdup. A Labview data acquisition system was used to control and collect all the desired data. A sampling rate of 1 time per second is programmed into the Labview. Time averaging was applied to the collected data in order to get the desired data point. Table 5.2 presents a list of the combinations of air and water flow rates for the first set of tests. Each test was repeated 3 times. 
Table 5.2 - First Set of Two-Phase Tests

\begin{tabular}{|c|c|c|}
\hline \multirow{2}{*}{$\begin{array}{r}{ }^{\top} \\
\left.F^{0}\right)\end{array}$} & \multicolumn{2}{|c|}{80} \\
\cline { 2 - 3 } & $\begin{array}{c}\mathrm{Qg} \\
(\mathrm{SCFM})\end{array}$ & $\begin{array}{c}\mathrm{Ql} \\
(\mathrm{GPM})\end{array}$ \\
\hline 100 & 60 & 100 \\
\hline 200 & 60 & 150 \\
\hline 300 & 60 & 200 \\
\hline 400 & 60 & 250 \\
\hline 400 & 60 & 300 \\
\hline
\end{tabular}

For each combination of water/air flow test, liquid holdup was measured by using two quick-closing valves, which are installed at the beginning and the end of the annular test section. When steady state was reached, the valves are closed nearly instantaneously. At the same time, a bypass valve was opened to allow the fluid to flow to the collection tower directly. So, a certain amount of air/water was trapped in the annular test section. Then, the air expansion tank was used to measure the volume of air inside the annular section. Also the nuclear densitometers can measure the mixture density, which, in turn, can be used to back calculate the liquid holdup. Figure 5.3 shows the measured differential pressures versus flow rates. 


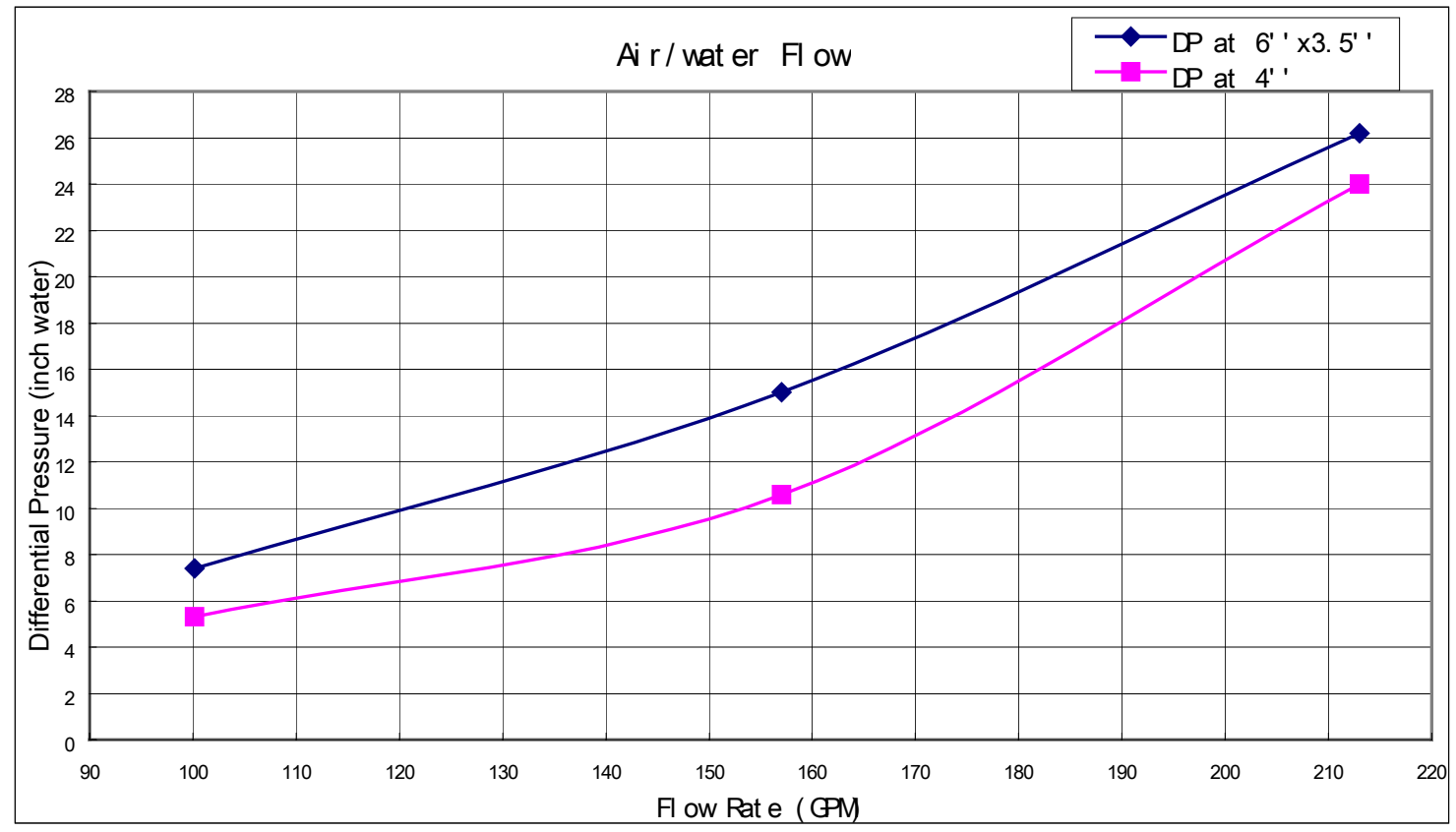

Figure 5.3 Differential Pressure at Annular Section and 4" pipe

\section{FUTURE WORK}

1. Calibration of Cuttings injection/collection system.

2. Continue air/water two-phase tests at EPET conditions.

3. Air/water/cuttings three-phase tests at EPET conditions.

4. Data analysis.

\section{Nomenclature}

$\mathrm{Q}=$ flow rate, GPM

$\mathrm{L} \quad=$ length, $\mathrm{ft}$

$\mathrm{D}=$ diameter, inch

$A=$ area, $\mathrm{ft}^{2}$

$\mathrm{OD}=$ outer diameter, $\mathrm{ft}^{2}$

ID = inner diameter, $\mathrm{ft}^{2}$

$D_{\text {hy }}=$ hydraulic diameter, inch

$D_{\text {eq }}=$ equivalent diameter, inch

$\mathrm{V} \quad=$ velocity, $\mathrm{ft} / \mathrm{s}$

$\mathrm{T} \quad=$ temperature, $\mathrm{F}$

$\mathrm{DP}=$ differential pressure, inch water

$\operatorname{Re}=$ Reynolds number

$\mathrm{F} \quad=$ friction factor 


$$
\begin{array}{ll}
\varepsilon & =\text { absolute pipe roughness, inch } \\
\mu & =\text { viscosity, } \mathrm{cp}
\end{array}
$$

\section{Subscripts}

$\begin{array}{ll}2 & =2 " \text { " pipe } \\ 3 & =3 " \text { pipe } \\ 4 & =4 " \text { pipe } \\ 6 & =6 " \text { " annular section }\end{array}$




\title{
6. DEVELOPMENT OF CUTTINGS MONITORING METHODOLOGY (Task 11)
}

\author{
Investigators: Kaveh Ashenayi and Gerald Kane (Profs Electrical Engr.)
}

\section{Objectives}

The ultimate objective of this task (Task 11) is to develop a non-invasive technique for quantitatively determining the location of cuttings in the annular (drilling) section of the ACTS Flow Loop. There are four different techniques that could be examined. However, as it was pointed out in the previous reports only three have good potential for success. These are Ultrasound, X-Ray/Gamma-Ray and Optical. Of these, we are concentrating on Ultrasound Transmitters and Sensors for Task 11.

\section{Team Composition:}

The team responsible for developing instrumentation to measure cuttings concentration and distribution within an annulus consists of Dr. Gerald R. Kane and Dr. Kaveh Ashenayi. Both are registered professional engineers and professors of Electrical Engineering Department at the University of Tulsa. MS level graduate students are assisting them. These students have BS degrees in EE and Computer Science. This particular combination works well since successful completion of this project requires skills from both disciplines. To achieve the objectives of this task, we will need to develop a very complicated electronic hardware/sensor and a software package that correctly interprets the ultra-sonic data received.

\section{Approach}

In subtask one of the Task 11 we are to develop a static (followed by a dynamic) radial test cell and to develop a preliminary set of instruments to detect the presence of cuttings in this cell.

The main approach to be investigated is the use of ultrasound transmission. We will investigate the need for an inner ring by comparing the results of two experiments. First we will setup a set of rings in the outer pipe. We will rotate the angle at which the sound is being transmitted relative to the sand collection. We will measure the sound received and compare it against sound transmitted. After suitable data processing we believe it is possible to get an acceptable picture of what is inside the pipe. This is very similar to the MRI technique used by physicians.

In the second experiment we will repeat the same experiment except we will setup an inner ring of sensors on the inner pipe. The inner ring will act as source and the outer ring will act as receivers. Then we will repeat the experiment above. 


\section{Progress to Date}

The sensor control board developed by our team has been further modified. A new board was hand assembled. A new printed circuit board is being produced. In addition, the firmware has been extensively modified to accommodate the features desired in the new board. Also, the data averaging on board have been tested.

We have further developed data collection/analysis software on the PC. The data collection part was further revised and tested in conjunction with the new board. The software will start by allowing the user to setup the communication characteristics of the system. The next step is to identify the number of boards connected. The data received from the sensor board is in the form of ASCII characters. The conversion algorithm that was developed has been tested. It enables calculation of the numerical voltage value corresponding to the character combinations that are received.

A set of software tools have been identified that will allow us to implement a neural network analysis package as part of the software for recording and processing data.

Additional tests have been conducted with a solid plastic cap covering the transmitter/receiver sets. The objective was to determine if contact with solid matter blocks the signal. The results indicated that the signals will be slightly attenuated but it is still functional.

Also, a clear plastic test cell was used to conduct some preliminary tests. The objective was to use this test cell and visually verify the results obtained from the sensor boards. The results seem to indicate that we are able to see and distinguish between different concentrations of sand. The next step is to classify the effects of shape and distributions of different concentrations.

\section{Future Work:}

We are to test the new hardware and firmware. At the same time we are implementing our data analysis software.

We propose to use the clear plastic cell to conduct two sets of experiments. First we will setup a set of rings in the outer pipe. We will measure the sound received and compare it against sound transmitted. After suitable data processing we believe it is possible to get an acceptable picture of what is inside the pipe.

In the second experiment, we will repeat the same experiment except we will use an inner ring of sensors. This consists of a ring of sensors in the inner pipe. The inner ring will act as source and the outer ring will act as receivers. We will use the same setup for calibrating the system.

We will use neural networks to model the effects of fluid flow on the signal received as well as the shape and distribution of the sand collection. This is needed due to the 
highly nonlinear nature of a slurry flow. It has been shown that neural networks can successfully model nonlinear systems.

We will setup a uniform bed of sand at the bottom of the clear plastic pipe. Shaking the pipe and letting the sand settle in water will accomplish this. Then we will make several measurements. This process will be repeated for different sand volumes. This procedure will provide different heights of sand at the bottom of the pipe. This will constitute the static calibration tests in a plastic pipe.

Finally, the static tests will be conducted in an all steel annulus, since steel pipes are used in both of the ACTS Flow Loops. Hence, it is anticipated that some changes will occur in the ultrasonic signals due to the different boundary conditions compared with the plastic cell. This will require some adjustments in the calibration to compensate for this change in pipe materials.

Next we will conduct the first of many dynamic tests. We will introduce an oscillatory motion. This will change the bed thickness. We will make measurements and compare our results against the static test results.

The next step will be to conduct dynamic tests in the small-scale experimental loop (Dynamic Testing Facility, see Section 7). At that time, the developed system will be used for measurements of cuttings concentration in the dynamic case of a flowing slurry. In the DTF the fluid will be moving but no drilling action can be simulated. Whether an ultrasonic system can be used in the full-scale ACTS Flow Loop with rotation of a simulated drillpipe will depend on whether reflected sound can be use or not. If only transmitted sound can be used, it will be significantly more difficult to mount the instrumentation on a rotating pipe and send the signals to a stationary receiver. 


\title{
7. DEVELOPMENT OF A METHOD FOR CHARACTERIZING BUBBLES IN ENERGIZED FLUIDS (TASK 12)
}

\author{
Investigator: Leonard Volk (ACTS Research Associate)
}

\subsection{Introduction}

Bubbles (as foam or aerated fluid) will be moving at a high rate (up to $6 \mathrm{ft} / \mathrm{sec}$ ) in the drilling section of the ACTF, and may be very small (down to $0.01 \mathrm{~mm}$ ). The bubble size and size distribution influence the fluid rheology and the ability of the fluid to transport cuttings. Bubbles in a shear field (flowing) may tend to be ellipsoidal which might alter both the rheology and transport characteristics.

This project is Task 12 (Develop a Method for Characterizing Bubbles in Energized Fluids in the ACTF During Flow) in the Statement of Work, and is divided into four subtasks:

- Subtask 12.1. Develop/test a microphotographic method for static conditions;

- Subtask 12.2. Develop/test a method for dynamic conditions;

- Subtask 12.3. Develop simple, noninvasive methods for bubble characterization;

- Subtask 12.4. Provide technical assistance for installation on ACTF.

Subtask 12.1 includes (1) magnifying and capturing bubble images, (2) measuring bubble sizes and shapes, and (3) calculating the size distribution and various statistical parameters.

Subtask 12.2 develops the methods needed to apply the results of Subtask 12.1 to rapidly moving fluids, especially the method of "freezing" the motion of the bubbles. A dynamic testing facility will be developed in conjunction with Task 11 for development and verification.

Subtask 12.3, added in year 3, develops simple, inexpensive and small-in-size methods for characterizing bubbles. This task was previously referred to as "New Techniques".

Techniques and methods developed under Subtask 12.2 and 3 will be applied to the drilling section of the ACTF in Subtask 12.4.

\subsection{Objective}

The objective of this task is to develop the methodology and apparatus needed to measure the bubble size, size distribution and shape during cuttings transport experiments. 


\subsection{Project Status}

\subsubsection{Dynamic Bubble Characterization}

\subsubsection{Dynamic Imaging}

A freestanding microscope bench was completed to decouple minor vibrations by the DTF from the microscope. Picture quality as seen on the video monitor or captured by the frame grabber is considerably poorer than viewed through the microscope itself. We are currently looking into the possibility of acquiring a microscope-mounted digital camera. Preliminary results indicate a much-improved image is possible. Software from MVTec (supplied by ThelmagingSource) has so far proven to be unsatisfactory, as has been the assistance by these companies in resolving problems with their product. Although challenging, we are pursuing other software that may allow us to capture bubble statistics directly. Several software packages can handle distinct objects with sufficient background contrast; however, our images are beyond their capabilities. We are currently determining the number of bubbles that must be counted (by size) to develop statistically significant parameters (mean, standard deviation, etc.).

\subsubsection{Dynamic Testing Facility}

Virginia Tech students and faculty visited this August to test flow sensors they are developing. This offered us the opportunity to calibrate the Moyno pump flow rate versus its RPM for water. The flow rate varied linearly from a minimum of $1.9 \mathrm{gpm}$ to a maximum of $23 \mathrm{gpm}$ (no differential pressure). A digital counter was added to the shaft of the Moyno pump to directly measure the RPM. Polycarbonate safety shields for the optical cell and sight cell are currently under construction. A drain in the low-pressure side of the Moyno pump has also been installed to facilitate removal of any foreign material, mostly flake rust. Modifications to the DTF are included in Figure 7.1, and a key for this figure is given below:

$\begin{array}{ll}\text { CCD: } & \text { Charge-Coupled Device } \\ \text { C: } & \text { Check Valve } \\ \text { CI: Corrosion Inhibitor } \\ \text { G: Pressure Gauge } \\ \text { NV: } \\ \text { P: } & \text { Pump } \\ \text { PD: } & \text { Photodiode } \\ \text { R: } & \text { Relief Valve } \\ \text { S: } & \text { Strainer or Filter } \\ \text { T: } & \text { Temperature Probe and Readout } \\ \text { V: } & \text { Valve } \\ \text { W: } & \text { Waste Fluid }\end{array}$

\subsubsection{Novel Techniques for Bubble Characterization}

Average bubble size. A prototype device for measuring the average bubble size has been constructed using a 2000\#, 1-1/2" pipe cross, two 3/8" NPT brass fittings, a pair of $10 \mathrm{~mm}$ windows, a photodiode and light from the microscope illumination 
source, directed to the prototype using a fiber optic cable. Preliminary data indicates that as the bubble size decreases, the prototype signal decreases as expected. As anticipated, the light intensity transmitted across the pipe also depends on the foam quality. A second light source is on order so that both the microscope and average bubble size device can be used simultaneously, allowing direct calibration of the prototype.

Foam Quality. Both $90^{\circ}\left(90^{\circ}, 45^{\circ}, 45^{\circ}\right)$ and equilateral $\left(60^{\circ}, 60^{\circ}, 60^{\circ}\right)$ prisms are available off-the-shelf. A $90^{\circ}$ prism allows reflected light to return parallel to the incident light, defeating one of the purposes of using a prism. Unfortunately the light entering an equilateral prism is totally internally reflected (as we need to use it). With the correct angle, a prism should give the desired results, but it will be a special order. Also, the spacing between the prism and the glass-foam interface of the glass window will be critical. Since developing this idea to use a prism as a means of directing light onto and retrieving a signal from the foam-glass interface, we have come up with a better method. The purpose of using a prism was to allow one to separate the first and second surface reflected light. By using a glass rod with one end cut at some angle other than $90^{\circ}$, only the reflection from the glass-foam interface will be measured by the photodiode. This concept is illustrated in Figure 7.2. It will require a shoulder to be ground onto the rod. However, once constructed, it should be much easier to use. We are currently looking for a company to help us fabricate these glass rods.

\subsection{Planned Activities}

\subsubsection{Dynamic Bubble Characterization}

- Locate a vendor with software adequate for our use.

- Locate a camera to give us clearer microscopic images.

\subsubsection{Novel Techniques for Bubble Characterization}

- Calibrate the average bubble size prototype

- Complete construction for the foam quality prototype and calibrate. 


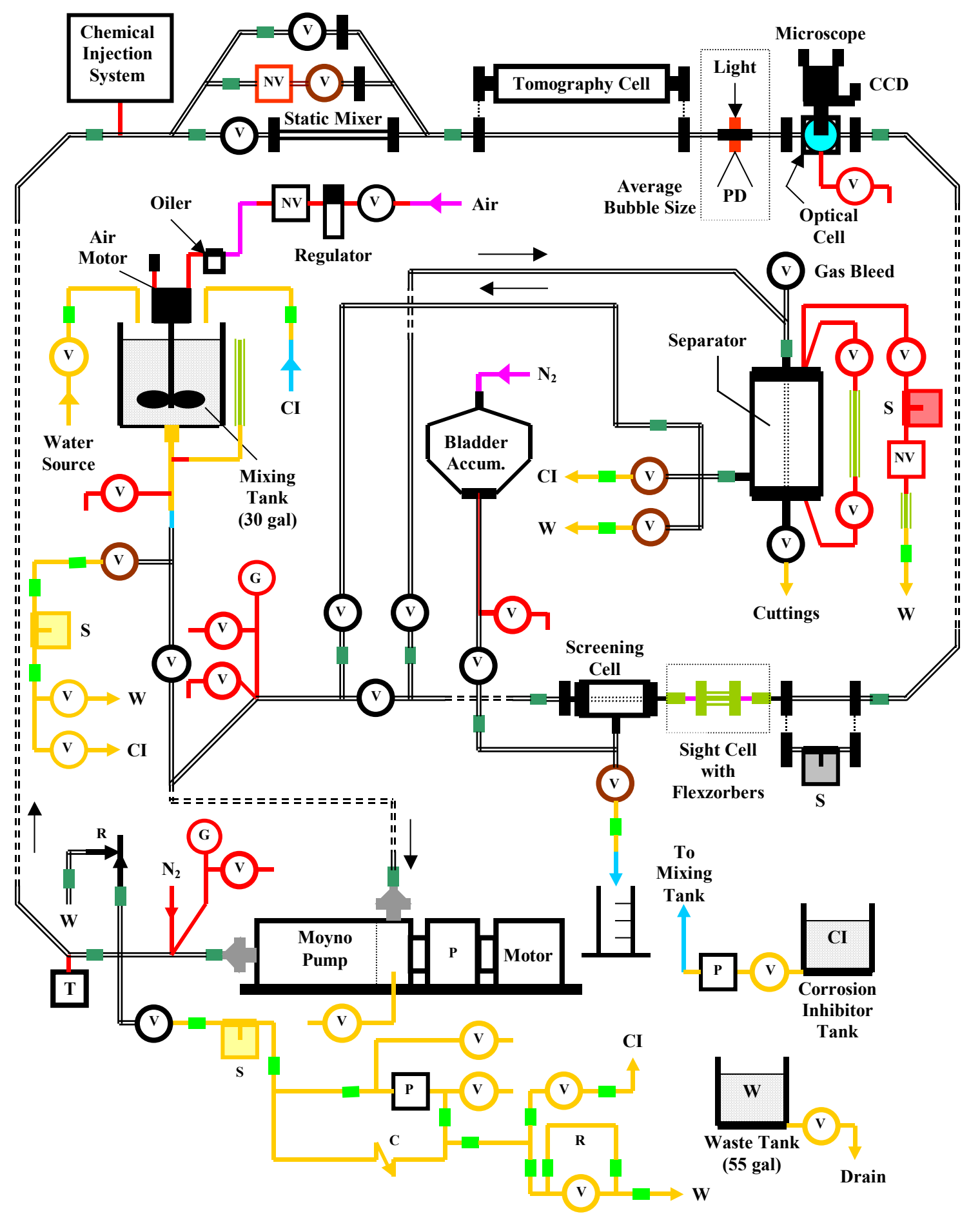

Figure 7.1. The Dynamic Testing Facility as of September 2002. 


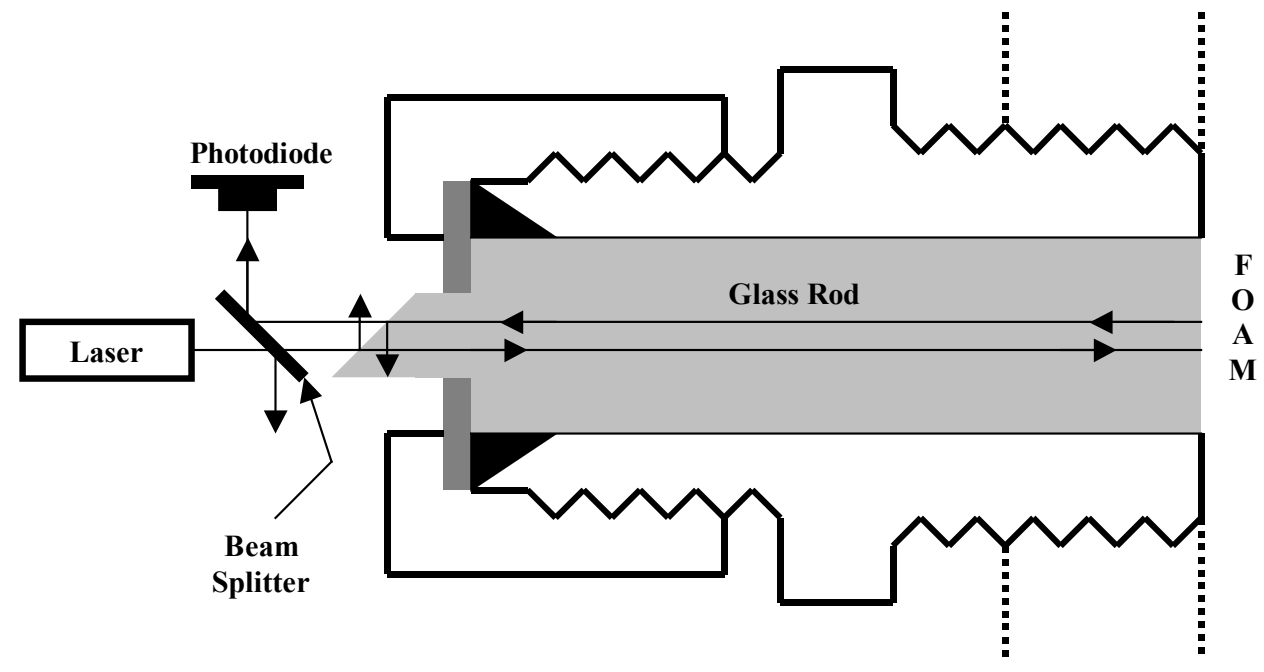

Figure 7.2 Method for determining the quality of foam 


\section{SAFETY PROGRAM (TASK 1S)}

\section{Chairman, Process Hazards Review Team: Leonard Volk (ACTS R.A.)}

\subsection{Introduction}

This project was initiated during the fourth quarter of 2000 to assess the hazards associated with the Advanced Cuttings Transport Facility (ACTF) and develop an Action Plan to address problems discovered during this Hazards Review. A Hazards Review is an industry accepted method used to improve the overall safety characteristics and reduce the possibilities of accidents in the work place. Each individual component of the ACTF is examined as to the effect and consequences on safety, health, and the environment, of the component in all possible operational modes. A Hazards Review can result in equipment modification, inspection and testing, documentation, personal protective equipment, personnel training, and/or emergency training. The hazards review process begins by selecting a review method. Next a team of qualified individuals must be formed. This team should include those knowledgeable in the review process and those familiar with the process to be reviewed. Prior to beginning the review, all available documentation needs to be gathered. This includes schematics, organized training, periodic inspections and testing results, design and construction documents, operating procedures, etc. Once the schematics have been verified and the operator of the equipment or process has reviewed its operation with the team, the Hazards Review begins. The review should continue uninterrupted until completed. After the findings and recommendations have been completed, a draft report is issued and reviewed by all team members, and the operator of the process or equipment. Following this review, any changes are incorporated and a final report issued. This completes the Hazard Review process. The operator then needs to develop an action plan to implement the recommendations from the Hazard Review. In our case, team members will participate in developing this plan.

\subsection{Objective}

The first objective of this task is to identify problems (findings) that might result in injury, property damage or the release of environmentally damaging materials and provide recommendations to minimize them, and to develop an action plan based on these recommendations.

A second objective is to establish standards for when a hazards review for the ACTS Flow Loop should be repeated.

A third objective is to develop a safety training course for all personnel that are involved in using the ACTS Flow Loop and equipment.

\subsection{Project Status}

Activities this quarter have continued on implementing the Action Plan and addressing several findings listed in the Hazard Review. Several pre-requisites exist 
before training can be completed. These have also been the focus of this quarter's activity.

\subsection{Planned Activities}

- Continue implementation of the Action Plan

- Prepare for review of latest modifications to the ACTF

- Begin designing and preparation of a safety training course. 


\section{TECHNOLOGY TRANSFER}

\section{Meetings with Petroleum and Service Companies}

ExxonMobil attended the May ABM and subsequently indicated an interest in joining the TU's JIP Projects. In addition, a visit was made to the Houston headquarters of MI Drilling Fluids. During this visit a presentation was made on the ACTS Project. The response from $\mathrm{Ml}$ was very positive, and they have also indicated an interest in joining the ACTS Project. Representatives from MI are expected at the next ABM in November.

Unfortunately, the merger between Conoco and Phillips has caused them to delay a decision about participating in the TU JIP Projects. A major restructuring of the company is underway. Since the merged companies will become the third largest petroleum company in the US, we will continue to be alert for the right timing to reinitiate our efforts to attract the new ConocoPhillips. In the mean time, we will continue to identify and contact other petroleum and service companies that will benefit by participating in this project.

\section{ACTS-JIP Advisory Board Meeting}

The next Advisory Board Meeting will held on November 19, 2002. In addition to the DOE, there are currently 10 member companies participating in the ACTS-JIP Project. They are: 1) British Petroleum, 2) Baker-Hughes , 3) ChevronTexaco, 4) Schlumberger Dowell, 5) Halliburton, 6) Intevep, 7) Petrobras, 8) Statoil, 9) TotalFina-Elf, and 10) Weatherford International. 